\title{
A Content Analysis of Celebrity-Endorsed Cosmetic Products in Fashion Magazines
}

\author{
Caroline Szwed
}

Follow this and additional works at: https://researchrepository.wvu.edu/etd

\section{Recommended Citation}

Szwed, Caroline, "A Content Analysis of Celebrity-Endorsed Cosmetic Products in Fashion Magazines" (2014). Graduate Theses, Dissertations, and Problem Reports. 6761.

https://researchrepository.wvu.edu/etd/6761

This Thesis is protected by copyright and/or related rights. It has been brought to you by the The Research Repository @ WVU with permission from the rights-holder(s). You are free to use this Thesis in any way that is permitted by the copyright and related rights legislation that applies to your use. For other uses you must obtain permission from the rights-holder(s) directly, unless additional rights are indicated by a Creative Commons license in the record and/ or on the work itself. This Thesis has been accepted for inclusion in WVU Graduate Theses, Dissertations, and Problem Reports collection by an authorized administrator of The Research Repository @ WVU. For more information, please contact researchrepository@mail.wvu.edu. 


\title{
A Content Analysis of Celebrity-Endorsed Cosmetic Products in Fashion Magazines
}

\author{
Caroline Szwed
}

\author{
Thesis submitted \\ to the Reed College of Media \\ at West Virginia University
}

in partial fulfillment of the requirements for the degree of

Master of Science in

Journalism
Steve Urbanski, Ph.D., Chair
Hongmin Ahn, Ph.D.
Gwen Bergner, Ph.D.
Emily Corio, MA.

Department of Journalism

\section{Morgantown, West Virginia \\ 2014}

Keywords: Celebrity, Body Type, Race, Ethnicity, Celebrity-Endorsement,

Copyright 2014 Caroline Szwed 


\title{
ABSTRACT \\ A Content Analysis of Celebrity Endorsed Cosmetic Products in Fashion Magazines
}

\section{Caroline Szwed}

\begin{abstract}
While there have been many studies examining celebrity-endorsed advertisements, few have studied the relationship between race and ethnicity and body types found in celebrity-endorsed advertisements. A sample of 265 celebrity-endorsed advertisements was collected from both Cosmopolitan and ELLE magazine during the first quarter of the year (January, February, March) between 2008-2013. A content analysis was constructed in order to determine the race and ethnicity of each celebrity found in the advertisement as well as their body type. The results suggest that there has been a tendency to use non-minority celebrities in celebrity-endorsed advertisements than non-minority celebrities. Furthermore, the findings demonstrate that most of the celebrities used within the advertisements closely identified with an ectomorph body type, which suggests that the majority of celebrity models used in celebrity-endorsed advertisements will have a thin and slender body type. The results of the study confirm that there has not been an increase in the prevalence of diverse celebrities, in terms of race and ethnicity, in these advertisements through 2008-2013 and that there is no relationship between race and ethnicity and body type.
\end{abstract}


A CONTENT ANALYSIS OF CELEBRITY ENDORSED COSMETIC PRODUCTS IN SZWED 3 FASHION MAGAZINES

\section{TABLE OF CONTENTS}

LIST OF TABLES..........................................................4

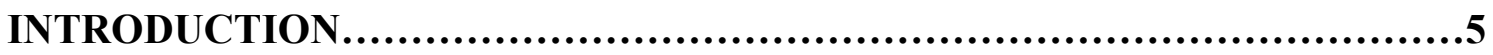

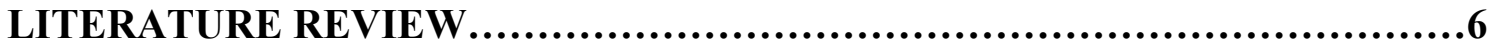

RESEARCH QUESTIONS.........................................................17

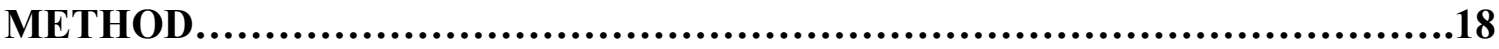

RESULTS............................................................................24

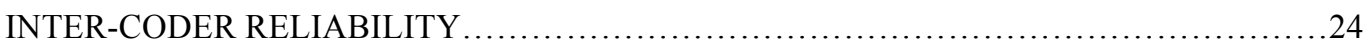

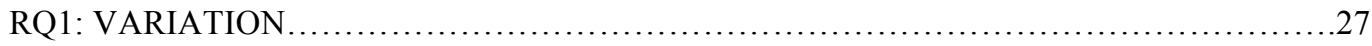

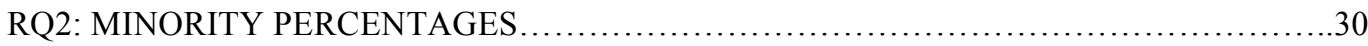

RQ3: BODY TYPES AND RACE AND ETHNICITY ................................... 32

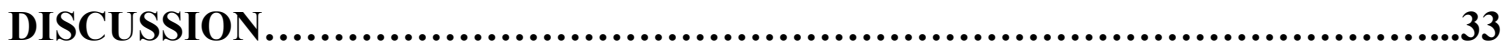

CONTRIBUTIONS AND IMPLICATIONS.................................38

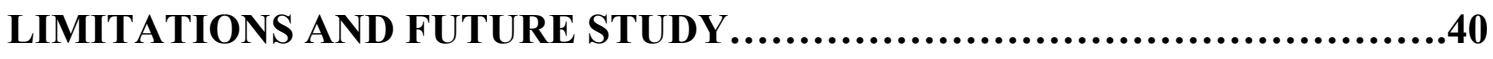

REFERENCES.............................................................42

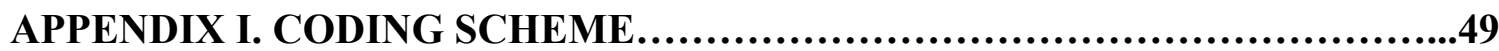


A CONTENT ANALYSIS OF CELEBRITY ENDORSED COSMETIC PRODUCTS IN SZWED 4 FASHION MAGAZINES

\section{TABLES}

TABLE 1: COSMOPOLITAN AND ELLE MAGAZINE INFORMATION ......................20

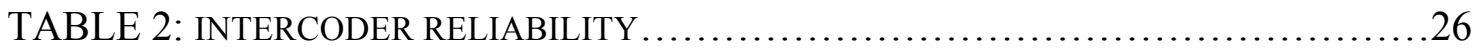

TABLE 3: FREQUENCY AND PERCENTAGES OF NON-MINORITY AND MINORITY GROUPS

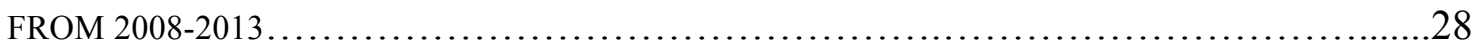

TABLE 4: DESCRIPTIVE ANALYSIS OF NON-MINORITY VS. MINORITY STATISTICS......30

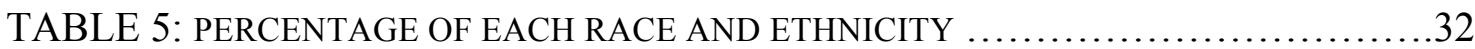

TABLE 6: BODY TYPE AND RACE AND ETHNICITY ................................ 


\section{INTRODUCTION}

With an exceedingly competitive economy, companies are discovering innovative ways to market and communicate their products to consumers. Strategic brand management- "a communication function based on how a brand targets the public and maintains a desired reputation of the brand, involves the design and implementation of marketing activities and measures and manages brand(s) to maximize their values" (Ogunsiji, 2012, p. 141). One of the most prevalent marketing techniques today is the use of celebrity endorsements. Celebrities are used to market products due to the fact that "they positively facilitate and attract consumers towards particular brands" (Ogunsiji, 2012, p. 141).

This thesis is a descriptive study that argues there has been an increase of diversity in racial and ethnic background from 2008-2013 in celebrity-endorsed cosmetic advertisements found in print magazines. Also, it will investigate whether there has been an increase in the use of "non-Caucasian" models in advertisements and establish if there is a correlation between body type, race, and ethnicity.

The study discusses how celebrities endorse beauty products to consumers assuming that the majority of the celebrities who advertise beauty products are generally considered "attractive." According to Mehrabian and Blum (1997), body shape has been found to be an important factor in what is considered to be "attractive": "Shapeliness of physique related to ratings of attractiveness in men and women" (p. 20). It was also found that, "obesity among individuals has been found to decrease attractiveness ... and height has been shown to be a determinant of attractiveness" (pp. 20-21). Appearance wise, this 
study will focus only on the attractiveness of a celebrity's body image presented in the advertisement.

The study suggests a positive shift in diversity in advertising over the past five years. According to Forehand and Deshpande (2001), consumers respond more positively to individuals of the same ethnicity: "Ethnic self-awareness leads to more positive evaluations of same ethnicity actors and spokespeople because it highlights the similarity between the consumer and spokesperson" (p. 339).

A content analysis of advertisements published between 2008-2013 in Cosmopolitan and ELLE magazine was conducted to determine whether there has been an increased use of celebrities of different race and ethnicities during this timeframe, as well as if there is relationship between race, ethnicity, and body type. Two independent coders were selected to code the advertisements. Once the advertisements were coded, Cohen's Kappa coefficient was used to measure the level of reliability between the two coders. After the results from the coders were recorded, a Statistical Package for the Social Sciences (SPSS) was used to compute all the numbers accurately to determine the overall results of the study. As a whole, this descriptive study will analyze celebrityendorsed beauty product advertisements in which body image and ethnicity will be evaluated.

\section{LITERATURE REVIEW}

The following literature review is compiled of articles that provide evidence, information, and support for this thesis. These articles contain information about celebrity endorsements, cosmetic advertisements, theory in advertising, ethnicity in advertising and the importance of image and body type in advertising. The majority of the information 
presented within the articles will be used in one form or another to answer the research questions within this study.

For this thesis, it is important to define what constitutes a celebrity. According to McCracken (1989), a celebrity is: "not only the usual movie and television stars but also individuals from the world of sport, politics, business, art, and the military" (p. 310). However, McCracken goes further into the definition of a celebrity and defines what a "celebrity endorser is":

The term "celebrity" is also meant in this article to encompass a variety of endorsements, including those in the explicit mode ("I endorse this product"), the implicit mode ("I use this product"), the imperative mode ("You should use this product"), and the co-present mode (i.e., in which the celebrity merely appears with the product). Moreover, it includes a range of endorsement roles, such as cases in which the celebrity is also an expert (e.g., Bobby Unser recommending motor oil), is associated with the manufacturer in some long-term capacity (e.g., Pat Summerall for TrueValue Hardware), or has no special knowledge of, or association with, the product in question (cf. Friedman, Termini \& Washington 1977, p. 310).

Therefore, this thesis looks at all celebrities shown in the selected magazines who are endorsing a beauty product. Also, understanding how celebrities influence consumers through advertisements is vital. However, understanding the relationship between celebrity and advertisement will be significant in determining this marketing strategy. McCracken (1989) offers another new approach to celebrity endorsements. As well as information about celebrity endorsements and advertising, McCracken shows the 
correlation between celebrities' effectiveness as endorsers and the cultural meanings with which they are given. The article provides a model and shows us how, "meanings pass from celebrity to product and from product to consumer" (p. 310). McCracken also offers a new theory - "transfer theory" -, which will be used throughout this thesis along with social cognitive theory. Transfer theory supports the notion that during a celebrity endorsement there will be something called an "association transfer" through a direction relationship between the celebrity in the advertisement and the product being advertised. The process allows the celebrity to "transfer" their perceived qualities to the actual product, which in turn makes the products more desirable. McCracken also provides his own definition of what a celebrity endorser "is" within an advertisement: "For present purposes, the celebrity endorser is defined as any individual who enjoys public recognition and who uses this recognition on behalf of a consumer good by appearing with it in an advertisement" (p. 310). McCracken's article offers significant information and perspectives that other articles do not.

LaWare and Moustatsos (2013) discuss transfer theory as well, which connects their research to McCracken's:

Celebrities serve the final state of meaning transfer because they are "super consumers" of a kind. They are exemplary figures because they are seen to have created the clear, coherent, and powerful selves that everyone seeks. They are compelling partners to the meaning transfer process because they demonstrate so vividly the process by which these meanings can be assembled and some of the novel shapes into which they can be assembled (p. 196). 
In addition to explaining McCracken's transfer theory, LaWare and Moustatsos' research is used in the method portion of this thesis as it provides substantial information useful to the product type variable used for this thesis. Their primary focus is on the celebrity's appearance and how their physical attributes are used to sell cosmetic products. This article provides useful information as it touches on the same variables as this thesis such as: cosmetics, a celebrity's physical appearance, and celebrity endorsed advertisements.

As transfer theory discusses why consumers are drawn to celebrity-endorsed advertisements, Seitz, Razzouk and Eamsobhan (2007) examine how celebrity endorsed advertisements have become a dominant form of advertising. Since this thesis looks only at celebrity-endorsed advertisements, this article offers an immense amount of useful research in regards to defining the purpose of celebrity-endorsed advertisements and why they are used as marketing strategies. According to Seitz, Razzouk and Eamsobhan:

Using celebrities in advertisements to sell products or services has be- come popular for many advertisers. The number and the dollar value of celebrity endorsement contracts are increasing, and these contracts constitute a significant and growing portion of advertising budgets. Marketers spend increasing amounts of money annually on celebrity endorsement contracts based on the belief that they are effective spokespeople for their product, creating a positive link between them and the brand image (p. 385).

This article is used throughout the methods portion of the thesis as it identifies celebrities as a variable and provides reasoning as to why this marketing strategy is important in advertising and in this thesis. 
This thesis only analyzes one "physical" attribute being the celebrity's body type. Therefore, it will be important to define body types. It is imperative to be able to identify a body type in an advertisement according to legitimate studies. According to the University of Houston's Center of Wellness Without Borders (n.d.), William Sheldon introduced the concept of three different body types that an individual may have (para. 1):

1. Ectomorphs - "are long and lean, with little body fat, and little muscle. Example: fashion models or basketball players" (para. 3).

2. Endomorphs - "have lots of body fat, lots of muscle, and gain weight easily. They're heavier and rounder individuals. Examples: Football linemen or Oprah Winfrey" (para. 4).

3. Mesomorphs — " are athletic, solid, and strong. They're not overweight and not underweight. Example: Jennifer Garner or Arnold Schwarzenegger" (para. $5)$.

Although the body types are defined, an individual still may have difficulty identifying and separating celebrities into each category. See figure 1.

Figure 1:
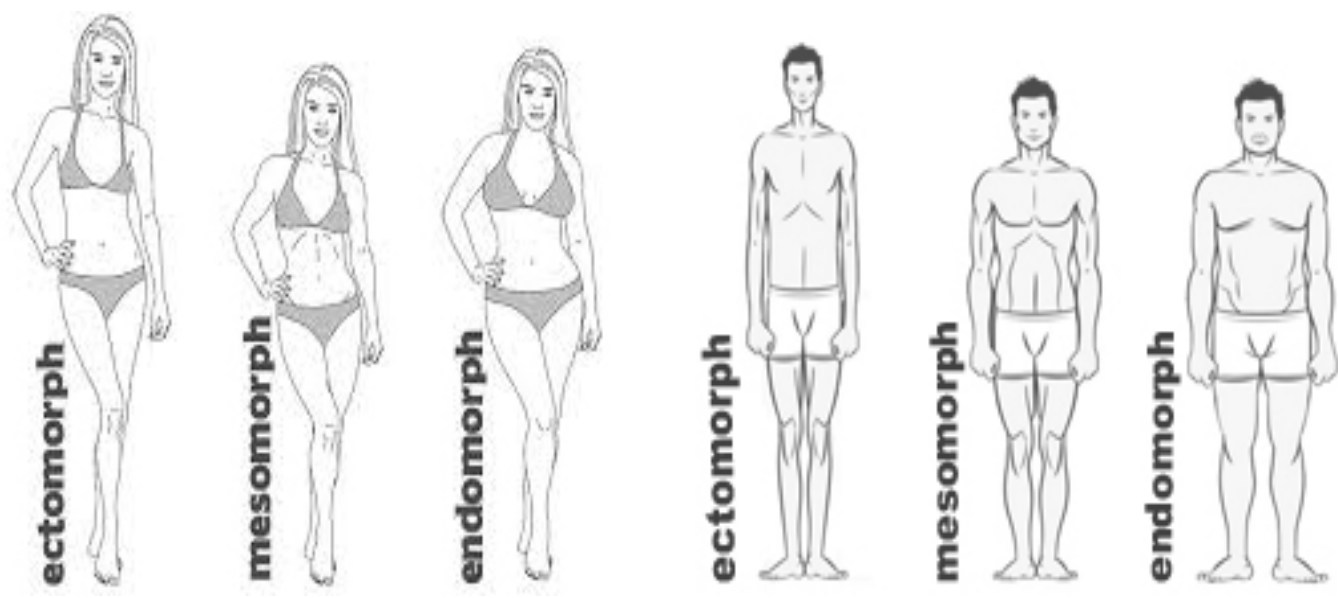
Mehrabian and Blum (1997) provide imperative information towards the thesis as they examine attractiveness and the components that make and individual attractive. Their study determined what kind of features of the face and body are deemed attractive according to a survey presented to college students in the United States. Their research provides this thesis with an understanding that body image makes an individual appear attractive or unattractive; however, it is only one component of attractiveness. Since body image will be the only factor of attractiveness being analyzed in this thesis, evidence will be needed that supports why this factor was chosen. According to Mehrabian and Blum, "Body shape has been found to be an important stable determinant of attractiveness. Shapeliness of physique related to ratings of attractiveness in men and women" (p. 20). This information is important if the research presents that celebrities do use their body image to sell products. It will show that individuals are attracted to others with an idealistic body and can enhance the effectiveness of an advertisement if a celebrity's body is revealed.

In order to understand the process behind celebrity-endorsed advertisements and why it is an important marketing strategy, one must understand theory behind it. In his book, Bandura (2001) defines his social cognitive theory, which is one of the primary theories of this thesis. Bandura provides a working definition of the social cognitive theory: One that “ $\ldots$ analyzes social diffusion of new styles of behavior in terms of psychological factors governing their acquisition and adoption and the social networks through which they spread and are supported" (p. 265). This theory will support the effect of celebrity endorsements on consumers because it reflects how a person's knowledge can be directly related to observing others through experiences, media influences and 
social interactions. According to social cognitive theory, individuals learn new behaviors through the replication of others. There are four factors in learning new behavior: 1) drives, 2) cues, 3) responses, and 4) rewards. These four factors suggest if an individual were to learn a new behavior, he or she would do so through observation. Therefore, consumers who see celebrity-endorsed products are more likely to "want to be" what they are seeing in the celebrity. By observing these advertisements, individuals are unintentionally creating images of their own reality through the mass media.

In their article, Forehand and Desphande (2001) begin to explain why in the past advertising has predominately used Caucasian models. However, with that explanation they also provide information as to why advertisers have been careful when using models of different ethnic background. They refer to ethnicity as a "power," and that it has the ability to target different communities. According to Forehand and Desphande, in the past, if a model of different ethnic background is used to market a product, they will be targeting that ethnic group of consumers. However, with the large amount of diverse celebrities advertising products, Forehand and Desphande find that this may reduce the consumer's willingness to purchase a product based on ethnicity. According to the researchers:

The prevalence of ethnic actors in current advertising has increased to the point that some ethnic groups are overrepresented in advertising relative to their composition in the general population. As a result, advertisements that once drew attention to ethnicity by simply featuring ethnic actors may no longer do so in today's multicultural environment. At a conscious level, increased ethnic presence in advertising may reduce the importance consumers place on ethnicity (p. 336). 
Forehand and Desphande's research will be critical in either showing there has been a shift from 2001 and how consumers relate to celebrities of different background or it will support the claim that consumers are just focused on the product regardless of the celebrity. This article offers insight on how there are now fewer advertisements on attracting consumers based on ethnicity.

In addition to race, ethnicity, and celebrity-endorsed advertisements, Carmichael and Francese (2011) discuss a variety of different statistics based on the 2010 census, which has significant value within for this thesis. They focus on the ethnic populations and demographics within the United States and how both have dramatically increased in the year of 2010. Their research provides depth for thesis thesis as it informs readers why there was such an increase in the data found for minority celebrities in 2010. In addition, The Start of Majority-Minority (2012) also contributes information about the 2010 census in saying that the minorities in the United States are now outnumbering non-minority individuals:

For the first time ever, the number of minority births outnumbered the number of births for non-Hispanic Whites in the first set of population estimates issued since the 2010 U.S. census (para. 2).

Information such as this is essential for this thesis because it provides reasoning as to why there was such an increase of minority celebrities used to advertise cosmetic products in 2010. Furthermore, The Economist (2011) provides statistics on advertising within the United States. Further into the article, it discusses how much of the nations marketing dollars are spent on ethnic targeted campaigns. This article ties everything together in regards to race and ethnicity in the U.S. and specifically how marketers seem 
to neglect using minority individuals in their campaigns/advertisements. This article will be used to explain why there were only two minority race and ethnicities found within 2008-2013 as well as why non-minority celebrities were used more in every single year studied.

Although the study shows that there is no correlation between race, ethnicity, and body type, it is important to provide rational for this study's third research question relating to all three variables listed above. Guzman \& Valdivia (2004) identified Latina actress, Selma Hayek as, "petite yet hyper-curvaceous frame [that] embodies the romanticized stereotypical Latina hourglass shape" (p. 212). Using the celebrities found in celebrity-endorsed advertisements in print magazines, Guzman and Valdivia look to see if there is a correlation between their body type and their race and ethnicity.

The study suggests that there has not been a shift in ethnicity over the past five years. However, it will be vital to understand the overall impact of a celebrity-endorsed products in marketing. Ogunsiji (2012) defines the importance of strategic marketing throughout his article and how beneficial the value of the delivery process is in our overly competitive society. This article not only demonstrates the impact of celebrity endorsements but also the impact those endorsements have on strategic brand management. The article provides an in-depth definition of what strategic brand management is and the prominence it has in advertising. Ogunsiji's research offers a different perspective on celebrity endorsements based on its investigation between the correlation of the success of celebrity endorsement brands and the influence of the brand in the market place. His study revealed that there is a $98 \%$ correlation between celebrityendorsed brands and the brand in the market place. Therefore, Ogunsiji supports the 
claim that by using celebrities, the image and desirability brand/product could gain more notoriety over its competitors. This study is relevant to this thesis because it will provide evidence that celebrity endorsements have a substantial impact on brand marketing, strategic marketing, and overall brand image.

Although this study looks at celebrity-endorsed advertisements, it is essential to note which media outlet these advertisements will be taken from and why this outlet was chosen for the study. Sebastian (2014) provides key numerical data for both magazines. He sets the parameters for this thesis for the advertisements found in the first quarter of the year (January, February, March). According to Sebastian's research, the top five fashion magazines (in terms of advertising) also had a large increase of advertisements in the month of March this year. Although the electronic database only dates back to 2008, it would be interesting to see how magazines start their New Year issue and how they progresses into the month of March, this year's most popular advertising month. The article provides statistics on both ELLE and Cosmopolitan magazines such as, "ELLE has 342 ad pages, up 3.3\%. This year marks ELLE's largest March issue since its recordbreaking 2008 edition and its highest revenue for a March issue, according to Hearst, the magazine's owner. Growth stems from ELLE's luxury business" (para. 5) and "Cosmopolitan will have 144 ad pages this March, up a page from last year, when it posted a $20 \%$ gain, the company said. Revlon returned to Cosmo after a three-year hiatus from the magazine, with a five-page spread" (para. 8). After compiling all of the advertisements in both magazines from the first quarter of the year from 2008-2013, there are a substantial amount of celebrity-endorsed advertisements. This article will be able to 
provide important percentages of growth in advertisements as well as the impact beauty companies/products have on both the magazines.

Once the sample of celebrity-endorsed advertisements was collected, the necessary data was collected for this study. Zeh (2005), Boetteger and Palmer (2010), and The University of Texas-Austin (2011) all provide information that helped frame a quantitative content analysis. In order to answer the research questions constructed for this thesis, a content analysis was selected to demonstrate the findings. Throughout these articles, one can find information on quantitative content analyses and how they are used for different studies. These articles were used to provide scholarly explanations as to why a content analysis was used for this thesis.

Once a content analysis was decided upon, Cohen's Kappa coefficient was used as a measurement of reliability for the data found. In Stemler's (2013) article he defines Cohen's Kappa coefficient, a measurement that was used throughout the thesis to ensure inter-coder reliability. He discusses that this statistic was developed to provide a percent agreement between coders when variables are being compared and are unevenly distributed. Information such as this is useful in this study as it specifies why Cohen's Kappa coefficient was used to determine the reliability. Stemler states that another reason studies use Cohen's Kappa coefficient is due to the amount of coders that the study is using: "Kappa is typically used with nominal level variables and is often seen in situations in which two independent raters have the task of classifying an object as belonging to a single level of a nominal variable" (para. 1). This thesis used two independent coders to code the sample of advertisements. 


\section{RESEARCH QUESTIONS}

The research questions for this thesis were informed and framed by the information outlined in the literature review. Upon writing the literature review, there was an immense amount of support that celebrities who endorse products are largely: attractive and have a desirable body image as well as the majority of celebrities are Caucasian. The use of celebrities in advertisements endorsing beauty products is often based on physical attractiveness (Belch \& Belch, 2013, p. 371). There is an overwhelming amount of evidence that individuals who appear in advertisements often have a "perfect" body. It has been proven that "mass media, due to their pervasiveness and reach, are probably the single most powerful transmitters of sociocultural ideals" (Tiggeman \& Mcgill, 2004, p. 24) and "visual media document a preponderance of young, tall, and extremely thin women who epitomize the current beauty ideal" (p. 24).

In addition to body type and physical attractiveness, this thesis looks to determine whether there has been an increase in the use of "non-Caucasian" models in advertisements and establish if there is a correlation between body type, race, and ethnicity. Through the thesis, research may or may not show how advertisers shifted their preference in race and ethnicity over the years or if they still primarily use Caucasian celebrities to sell beauty products. The thesis considers the following research questions:

RQ 1: Has there been an increase of minority racial and ethnic backgrounds over the last five years in celebrity endorsed advertisements? 
RQ 2: Among the non-white endorsers, what races/ethnicities are represented and what is the number/percentage of each (African American, Hispanic, Caucasian)?

RQ 3: What body types are most closely related to each racial and ethnic background demonstrated in the advertisement?

\section{METHOD}

In order to answer the research questions concerning race, ethnicity, and body type, a quantitative content analysis (CA) was conducted in order to accurately represent each question. According to Zeh (2005), a content analysis is a quantitative research instrument for a systematical and inter-subjective description of communication content starting from a research question (p. 2). In addition, a content analysis can be used as a ... research technique for making replicable and valid inferences from text and other meaningful matter in the context of their use. Texts can be broadly classified to include printed matter, images, maps, art, sounds, signs, or symbols (Boettger \& Palmer, 2010, p. 346).

Using a highly structured content analysis was the most appropriate approach for this thesis as it is a method that can demonstrate findings in media and media coverage. According to Zeh (2005), "the content analysis reduces the complexity of media coverage as it brings out the central patterns of the coverage" (p. 2). A content analysis would be most suitable for this study as the study focuses on advertisements found in magazines.

\section{Sample}

The thesis will analyze two magazines: Cosmopolitan and ELLE magazine. These two magazines were chosen because they are the two top fashion magazines in terms of 
advertisements. ELLE has up to 342 ad pages, while Cosmopolitan has up to $144 \mathrm{ad}$ pages in their last issue (Sebastian, 2014, para. 5-8). The data will come from the years 2008-2013. Initially, the timeframe was proposed to encompass a 10-year span (20032013); however, the magazines offered in the electronic database only went back to 2008 . The first quarter of the year will be used: January, February, and March to construct this study due to a time limit in which more months in the magazine could not be analyzed effectively. A total sample of 265 celebrity-endorsed beauty product advertisements was selected for this study.

\section{Coding Scheme}

In this content analysis, a coding scheme was created in order to obtain information relating to the thesis topic. The coding scheme includes variables that are analyzed throughout the content based on body type, race, and ethnicity. The celebrityendorsed advertisements from ELLE and Cosmopolitan magazine from the years 20082013 were accessed online through a website called, Zinio. The full issue of the magazine was provided from the cover to the last page. All celebrity-endorsed advertisements were printed and organized into a folder based on year, month, and magazine. In order for an advertisement to be considered for this content analysis, the celebrity had to be recognizable and the advertisement page had to be more than 25 percent of the page. The self-promoting advertisements devoted to ELLE and Cosmopolitan magazine commonly called "house ads" - were not included in the sample.

Magazine: According to the Association of Magazine Media, "magazines account for 15 percent of total advertising expenses in the United States, while 93 percent of adults (18 and older) read magazines with the average reader spending approximately 42 
minutes on each issue" (Belch \& Belch, 2013, p. 370). If one looks at Cosmopolitan and ELLE magazines rate cards (2013) they provide substantial statistics, percentages, and facts about both magazines. This will be important information to use throughout the introduction of the thesis, as it will provide information as to why the magazines were chosen. See Table 1 for information about both magazines:

Table 1: Cosmopolitan and ELLE magazine information

\section{COSMOPOLITAN}

Total Audience:

Female Viewers:

Viewers Reading/Month:

Rate Base:

Target Audience:

Median Age:

Print Circulation:

Readership:
16.98 million

14.46 million

+21 million

3 million

18- to 34-year-old women

28

279,127

1.36 million

\section{ELLE}

5.64 million

5.08 million

+21 million

1.1 million

18- to 49-year-old women 28

166,680

876,000

Cosmopolitan and ELLE's Media Kits (2013) provide the magazine's information where one can view essential statistics regarding the magazines' growth in the past year. The websites note target audiences and each magazine's marketing techniques. The websites also offers PDF's listing statistics and percentages of most recent years.

Type of Celebrity: Previous research has shown that using celebrities to endorse products has become a part of "... a marketing communications strategy, the use of 
celebrities is a fairly common practice for major firms in supporting corporate or brand image goals. Companies, across all industries, use celebrity endorsements" (Seitz \& Razzouk \& Eamsobhan, 2007, p. 384). For this thesis it is important to define what a celebrity is as only celebrity-endorsed advertisements were looked at in both ELLE and Cosmopolitan magazine. According to McCracken (1998), celebrities can be defined as individuals who go beyond usual "movie and television" stars. They also can be defined as “... individuals from the world of sport, politics, business, art, and the military" (p. 310). Based on this definition of a celebrity, the coding sheet constructed for this thesis provided a category for each type of celebrity.

Product Type: This thesis looks at cosmetic products because as it has been proven that audiences pay more attention to their appearance based on these advertisements. According to LaWare and Moustatos (2013), a celebrities appearance "in the ads lend an aura of authenticity to the beauty products being sold, suggesting, in effect, that the products featured in the ads have enabled them to remain attractive and stay visible and viable as actors" (p. 192). Also, since this research focuses primarily on celebrity-endorsed advertisements that market cosmetic products, it is essential that the coding sheet provide every type of cosmetic product. The Association of Southeast Asian Nations provides a definition of what is considered a cosmetic product. The product type portion of the coding sheet was based on their definition of what can be classified as a "cosmetic product." The coding sheet lists twenty different categories of a cosmetic product.

Celebrities Body Type: In terms of body type, this study only looks at celebrityendorsed advertisements that featured the celebrity's full body. If there was a celebrity- 
endorsed advertisement that only featured the celebrity' face, that particular advertisement was not used in the body type sample. According to Tiggeman and Mcgill (2004), "It was found that exposure to either body part or full body images led to increased negative mood and body dissatisfaction" (p. 23). Through the years the media have been using thin models to market products in advertisements: "This model maintains that current societal standards for beauty inordinately emphasize the desirability of thinness, and thinness at a level impossible for many women to achieve by healthy means" (Tiggeman \& Mcgill, 2004, p. 23). This study uses William Sheldon's concept of three different body types to distinguish the trend in body types over the past five years. Also, the study is designed to determine if there is a connection between race and body type among models. According to the U.S. National Library of Medicine National Institutes of Health (1998):

Caucasian and Hispanic-Americans showed more weight-related body image disturbance than African-Americans and Asian-Americans. African-Americans had the most positive general appearance body image. Ethnic groups were generally similar in their ideal body image traits but some differences occurred for the valuing of skin color and breast size (para. 3).

Celebrities Ethnicity: Since this study is primarily focused on a celebrity race and ethnicity, it will have to provide a list of categories that race and ethnicity can be divided into. According to the Center for Disease Control and Prevention (2014), the U.S. Office of Management and Budget's (OMB) required federal agencies to use a minimum of five race categories:

White, Black or African American, American Indian or Alaska Native, Asian, 
and Native Hawaiian or Other Pacific Islander. For respondents unable to identify with any of these five race categories, OMB approved the Census Bureau's inclusion of a sixth category — Some Other Race — on the Census 2000 and 2010 Census questionnaires (p. 2).

In addition to the 2010 Census, Hispanic origin "included five separate response categories and one area where respondents could write-in a specific Hispanic origin group. The first response category is intended for respondents who do not identify as Hispanic. The remaining response categories ['Mexican, Mexican Am., or Chicano'; 'Puerto Rican'; 'Cuban'; and 'Another Hispanic, Latino, or Spanish origin'] and write-in answers can be combined to create the OMB category of Hispanic" (p. 2)

The Center for Disease Control and Prevention also provides a definition of each race. For example they define "African-American" as:

The Black or African American population includes people who marked their race(s) as "Black, African Am., or Negro" or reported entries such as African American; Sub-Saharan African (e.g., Kenyan and Nigerian); or Afro-Caribbean such as Haitian and Jamaican according to the US Census Bureau (Black or African American Populations, para. 1).

It was imperative to define each race, as this variable can be subjective. The coders needed to be provided with a substantial definition of each race to lessen subjectivity as much as possible. Although definitions of what each race and ethnicity are classified as were provided on the coding sheet, the independent coders assigned race and ethnicity based on visual appearance. The coders self-identified each celebrity's race and 
ethnicity based on their phenotypes according to the U.S. government definition provided on the coding sheet.

\section{RESULTS}

\section{Inter-coder Reliability}

In order to ensure the content analysis presents a valid study, inter-coder reliability will be used to assess the advertisements based on the coding scheme. Two Caucasian males were selected to code the advertisements used for this study. Both coders were trained prior to coding the advertisements. During their training, the coders were instructed on the coding process to ensure consistency throughout the study. In order to accurately confirm that the two coders were reliable, 10 percent of the sample, 27 advertisements, was randomly drawn from the original sample of 265 advertisements. These advertisements were not used in the final sample as they were used to determine the reliability between coders and could not be used in the overall sample.

The independent coders were used to measure the consistency throughout the study. Cohen's Kappa coefficient was used to measure the agreement between the two coders. Also, Statistical Package for the Social Sciences (SPSS) was utilized to compute all the numbers accurately in order to efficiently calculate inter-coder agreement and reliability. A descriptive and chi-square analysis was used throughout this study as the study considered two descriptive variables. According to Stemler (2013):

Cohen's kappa statistic was developed to correct for the problem of inflated percent agreement statistics that occur when marginal values on the variables being compared are unevenly distributed. Kappa is typically used with nominal level variables and is often seen in situations in which two independent 
raters have the task of classifying an object as belonging to a single level of a nominal variable (para. 4).

Each of the variables presented within this study were examined using Cohen's Kappa percentage agreement. According to this statistical measure of inter-coder reliability Cohen's Kappa ranges from 0-1.00 and a Kappa $>.70$ is considered satisfactory. When raters are in complete agreement, $\mathrm{K}=1$. 
Table 2: Inter-coder Reliability for each variable presented in the study

\begin{tabular}{|c|c|c|}
\hline Variables: & Functioning Definition & Ir \\
\hline $\begin{array}{l}\text { Type of } \\
\text { Celebrity }\end{array}$ & $\begin{array}{l}\text { Actor/actress, artist/performer, athlete, } \\
\text { business professional, military }\end{array}$ & 0.930 \\
\hline $\begin{array}{l}\text { Type of } \\
\text { Magazine }\end{array}$ & Cosmopolitan and ELLE magazine & 1.0 \\
\hline Month & First quarter of the year: Jan., Feb., Mar. & 1.0 \\
\hline Year & Years ranging from 2008-2013 & 1.0 \\
\hline $\begin{array}{l}\text { Type of } \\
\text { Product }\end{array}$ & $\begin{array}{l}\text { Creams: emulsion, lotions, gels, oils; Face } \\
\text { masks, tinted bases: liquid pastes/powders, } \\
\text { make up powders, after bath powder, toilet } \\
\text { soaps, deodorant soaps, depilatories, } \\
\text { deodorants, anti-per spirants, hair care } \\
\text { products, shaving products: creams, foams, } \\
\text { lotions; products for making up and removing } \\
\text { make up from the face and eyes, products for } \\
\text { the lips, products for teeth and mouth, products } \\
\text { for external intimate hygiene, sunbathing products, } \\
\text { products for tanning without sun, skin-whitening } \\
\text { products, anti-wrinkle products }\end{array}$ & 0.77 \\
\hline $\begin{array}{l}\text { Face or } \\
\text { Body }\end{array}$ & $\begin{array}{l}\text { Understanding what advertisements portrayed } \\
\text { a celebrity's face (neck and up) or their body } \\
\text { (neck and down) }\end{array}$ & 1.0 \\
\hline $\begin{array}{l}\text { Type of } \\
\text { Body }\end{array}$ & $\begin{array}{l}\text { Ectomorph: long and lean with little body fat } \\
\text { and little muscle. Endomorph: lots of body fat, } \\
\text { lots of muscle, and gains weight easily: heavier, } \\
\text { rounder individuals. Mesomorph: athletic, strong, } \\
\text { they are not overweight and not underweight. }\end{array}$ & 0.90 \\
\hline Gender & Male or female & 1.0 \\
\hline Ethnicity & $\begin{array}{l}\text { Caucasian, African American, American } \\
\text { Indian, Native Hawaiian, Asian, Hispanic/ } \\
\text { Latino, Other. }\end{array}$ & 0.82 \\
\hline
\end{tabular}




\section{RQ 1: Variation}

The first research question asked if there has been an increase of minority racial and ethnic backgrounds over the last five years in celebrity endorsed advertisements. The data analyzed suggests that in the five-year period studied, there was not an increase of minority celebrities in celebrity-endorsed advertisements. Originally, the study was designed to perform a Chi-Square analysis to determine if there is a relationship between the two variables, year and ethnicity/diversity as well as if there is a significant difference by year. Overall, Chi-Square $\left(\mathrm{X}^{2}=17.23, p<.01\right)$ determined that there was a significant difference between the relationship of race/ethnicity and years. This can be verified through the p-value by recognizing that it is less than 0.01 , which shows that the relationship between these variables is significant. Furthermore, the study showed that one or more of these data points is statistically unlikely to happen but it is unclear as to which one it would be.

Additionally, a descriptive analysis was performed. This study showed that during the span between 2008-2013, only two types of race and ethnicity aside from Caucasian were used in celebrity endorsed advertisements. The two races identified, as "minorities" in this study, are African Americans and Hispanics. Since only two minority groups were recognized in the study, these two race and ethnicities were categorized together under "minorities." Table 2 shows the variation from 2008-2013 between the non-minority and minority groups used in celebrity endorsed advertisements. A "total" table is also provided to demonstrate the sample as a whole and how it correlates to the numbers drawn from both the non-minority and minority group. 
Table 3: Frequency and percentage of non-minority and minority groups from 2008-2013

Total $\mathrm{N}=183$

Non-Minority

$\begin{array}{llllll}2008 & 2009 & 2010 & 2011 & 2012 & 2013\end{array}$

$\% \quad 78.8 \%(41) \quad 67.6 \%(25) \quad 58.6 \%(17) \quad 85.7 \%(30)$
Within
Year

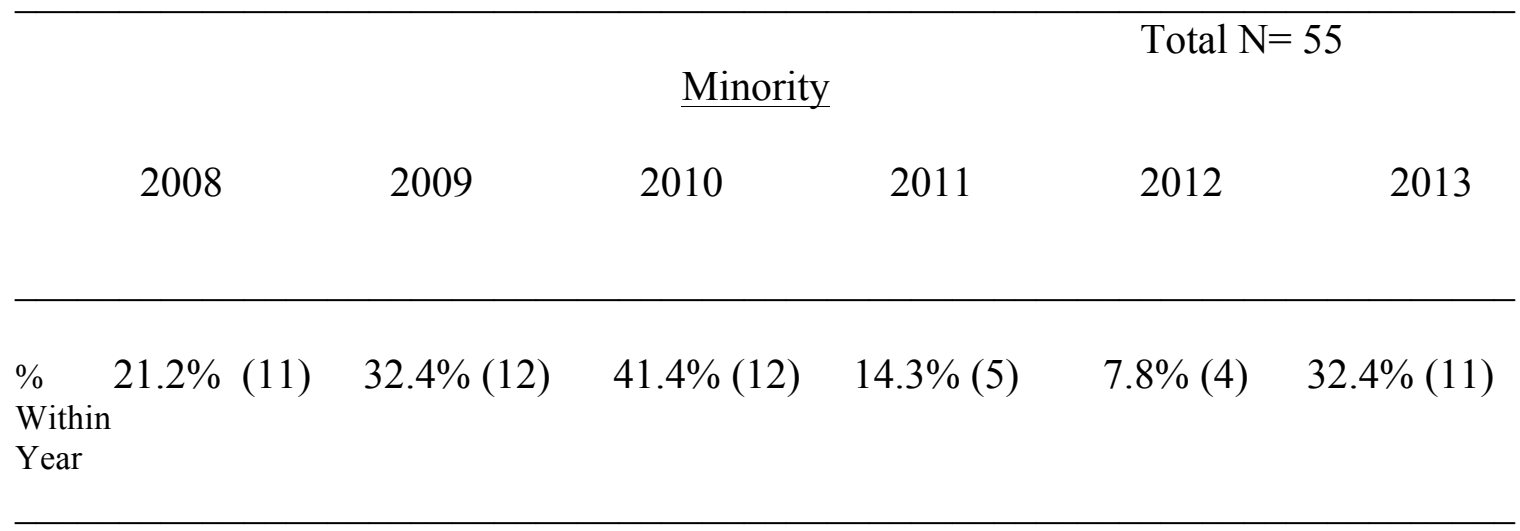

The research found that there was a significant use of non-minority celebrities as opposed to minority celebrities during the years of 2008, 2009, 2011, 2012, and 2013. In 2008, from a sample of 52 celebrity-endorsed advertisements, $41(78.8 \%)$ of them were non-minority models while the remaining $11(21.2 \%)$ advertisements were minority celebrities. In 2009 one can see a similar trend as a sample of 37 advertisements depicted $25(67.6 \%)$ non-minority advertisements and only $12(32.4 \%)$ showed celebrities classified as a minority. The year of 2011 represented a sample of 35 celebrity-endorsed advertisements in which $30(85.7 \%)$ represented non-minority celebrities while the remaining 5 advertisements $(14.3 \%)$ were minorities. One can see a larger gap between minority vs. non-minority in 2012. In a sample of 51 advertisements, 47 (92.2\%) were non-minority celebrities while only $4(7.8 \%)$ of the sample were shown to be minority 
celebrities. The most recent year, 2013 is represented by a sample of 34 advertisements in which $23(67.6 \%)$ of them were non-minority advertisements and $11(32.4 \%)$ were minority advertisements.

However, although the majority of the years $(2008,2009,2011,2012$, and 2013) had a significant difference in the use of non-minority celebrities used as opposed to minority celebrities. The year of 2010 represented a closer range in racial and ethnic groups. From a sample of 29 celebrity-endorsed advertisements, 17 (58.6\%) of them were non-minority celebrities, while $12(41.4 \%)$ of the remaining advertisements were shown to be minority celebrities. 2010 demonstrates a much closer relationship between Caucasian, African American, and Hispanic celebrities used to advertise cosmetic products.

Overall from 2008-2013, the total sample of 238 celebrity-endorsed advertisements revealed that $183(76.9 \%)$ advertisements were non-minority while only $55(23.1 \%)$ were minority celebrities.

To understand the results of this research question more clearly, a descriptive analysis was constructed to analyze the data more visually. Table 4 demonstrates the decrease in non-minority celebrities compared to minority celebrities in 2010 as well as the increase of non-minority celebrities compared to minority celebrities in 2012 and 2013. 
Table 4: Descriptive analysis of non-minority statistics vs. minority statistics

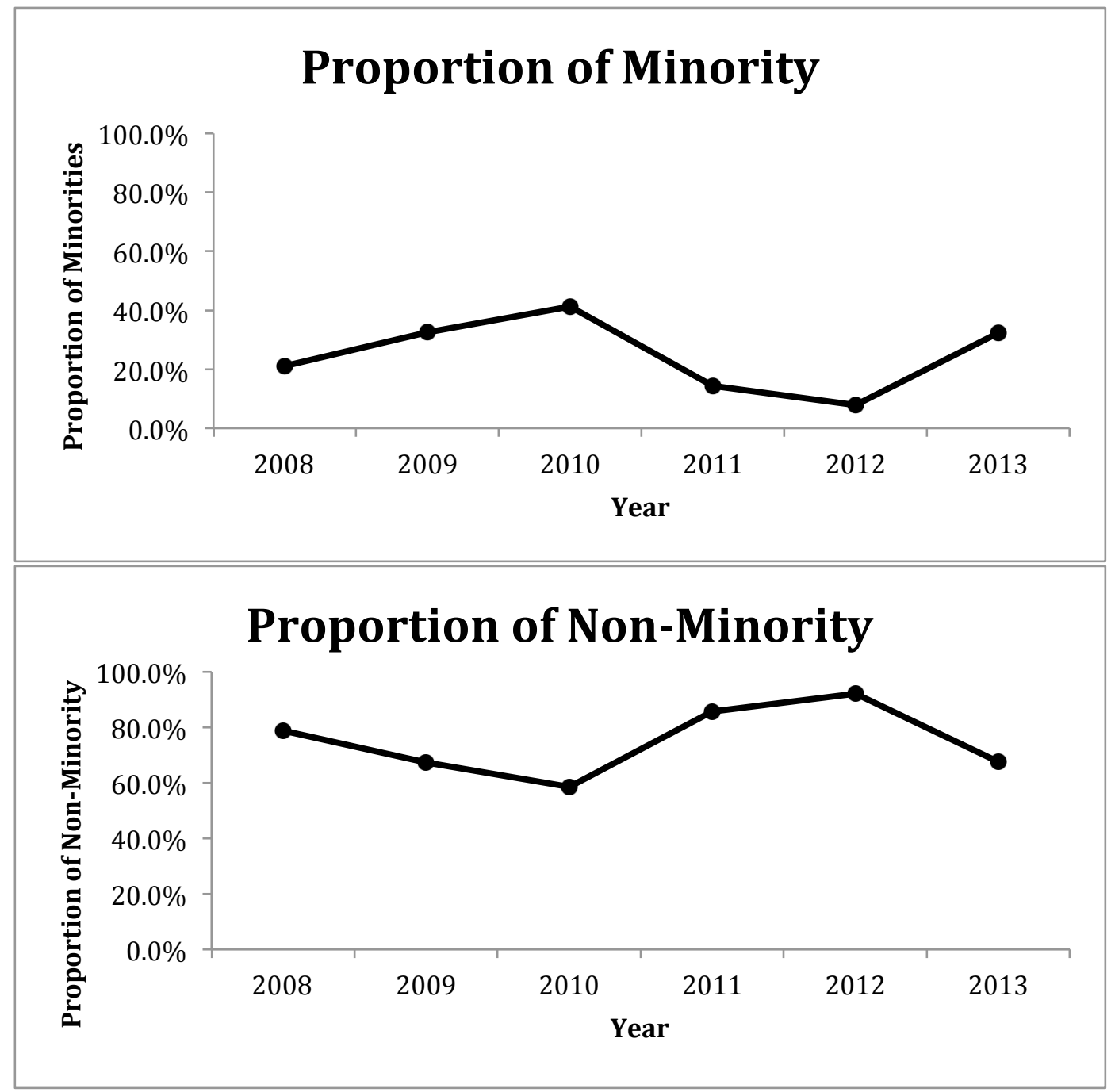

Overall, based on the results of this study, if one looks at the proportions capturing and measuring the non-minorities in celebrity-endorsed cosmetic advertisements, it is apparent that there is not an increase of non-minority celebrities.

\section{RQ2: Minority Percentages}

The second research question asks what percentage of races/ethnicities is represented from the study. Another descriptive analysis was conducted for this research 
question, as it would most accurately depict the percentages of minority race and ethnicities demonstrated in the study.

Table 4 demonstrates all the percentages within this study concerning minority representation within celebrity-endorsed advertisements. It is important to note that the term, "code ethnicity" represents a number or percentage that describes both African American and Hispanic celebrities within the study.

According to Table 4, between the years of 2008-2013, that compiled a total sample of 238 advertisements, 183 (76.9\%) were associated with non-minority celebrities and only $55(23.1 \%)$ were associated with minority celebrities. Of the combined total of $55(23.1 \%)$ minority celebrity endorsed advertisements, $15.1 \%$ of them were African American celebrities while the remaining 8.0\% were Hispanic celebrities.

Table 4 also provides separate information on both minority race/ethnicities. According to Table 4, between the years of 2008-2013 out of the sample of 238 advertisements, $36(15.1 \%)$ of them were African American celebrities. Furthermore, from the same sample of 238 advertisements, $19(8.0 \%)$ of them were Hispanic celebrities. It is important to note that the label, "Code Ethnicity" shown in Table 4 represents combined minority race and ethnicities: African American and Hispanics. 
Table 5: Percentage of each race and ethnicity

\begin{tabular}{|c|c|c|c|c|}
\hline \multirow[b]{2}{*}{ Ethnicity } & \multicolumn{4}{|c|}{ Code Ethnicity } \\
\hline & & Non-Minority & Minority & Total \\
\hline Caucasian & Count: & $\mathrm{N}=183(100 \%)$ & $\mathrm{N}=0(0 \%)$ & $\mathrm{N}=183(76.9 \%)$ \\
\hline $\begin{array}{l}\text { African } \\
\text { American }\end{array}$ & Count: & $\mathrm{N}=0(0 \%)$ & $\mathrm{N}=36(65.5 \%)$ & $\mathrm{N}=36(15.1 \%)$ \\
\hline Hispanic & Count: & $\mathrm{N}=0(0 \%)$ & $\mathrm{N}=19(34.5 \%)$ & $\mathrm{N}=19(8.0 \%)$ \\
\hline Total & Count: & $\mathrm{N}=183(76.9 \%)$ & $\mathrm{N}=55(23.1 \%)$ & $\mathrm{N}=238(100 \%)$ \\
\hline
\end{tabular}

\section{RQ 3: Body Type and Race and Ethnicity}

The third and final research question concerns the relationship between race and ethnicity and body type. The data suggests that in the five-year period studied the body type most closely related to each racial and ethnic background demonstrated in celebrityendorsed advertisements was an ectomorph body type. A Chi-Square analysis was performed for this research question as it was measuring the significance between race/ethnicity (Caucasian, African American, Hispanic) and three body types (Ectomorph, Endomorph, Mesomorph). The Chi-Square analysis $\left(\mathrm{X}^{2}=6.31, p=0.18\right)$ determined that there is no statistical significance between cells and could not confirm that there is a relationship between race/ethnicity and body type.

According to Table 6, the majority of body types used in celebrity-endorsed cosmetic advertisements are Ectomorphs for Caucasians, African Americans, and Hispanic celebrities. It is important to note that the sample of 238 advertisements was not all considered for this test. Out of 238 advertisements, only 80 (33.6\%) advertisements 
showed a celebrity's body. The remaining $158(66.4 \%)$ of the advertisements showed only a celebrity's face. Those advertisements were not included in the Chi-Square analysis. Overall, 68 out of $80(85 \%)$ advertisements portrayed celebrities that have an Ectomorph body, 7 out of $80(8.8 \%)$ advertisements portrayed an endomorph body, and five out of $80(6.2 \%)$ advertisements portrayed a mesomorph body.

Table 6: Body Type and Race/Ethnicity

\begin{tabular}{|c|c|c|c|c|}
\hline \multirow[b]{2}{*}{ Ethnicity } & \multirow[b]{2}{*}{ Ectomorph } & & \multicolumn{2}{|c|}{ Total $\mathrm{N}=80$} \\
\hline & & $\frac{\text { Body Types }}{\text { Endomorph }}$ & Mesomorph & Total \\
\hline Caucasian & $\mathrm{N}=53(88.3 \%)$ & $\mathrm{N}=4(6.7 \%)$ & $\mathrm{N}=3(5 \%)$ & $\mathrm{N}=60$ \\
\hline African & & & & \\
\hline American & $\mathrm{N}=9(64.3 \%)$ & $\mathrm{N}=3(21.4 \%)$ & $\mathrm{N}=2(14.3 \%)$ & $\mathrm{N}=14$ \\
\hline Hispanic & $\mathrm{N}=6(100 \%)$ & $\mathrm{N}=0(0 \%)$ & $\mathrm{N}=0(0 \%)$ & $N=6$ \\
\hline Total & $\mathrm{N}=68(85 \%)$ & $\mathrm{N}=7(8.8 \%)$ & $\mathrm{N}=5(6.2 \%)$ & $\mathrm{N}=80$ \\
\hline
\end{tabular}

\section{DISCUSSION}

The purpose of this study was to determine whether there has been an increase of diversity in racial and ethnic background form 2008-2013 in celebrity-endorsed cosmetic advertisements. In addition, this thesis looked to examine if there has been an increase in the use of "non-minority" or "minority" models in advertisements and establish if there is a correlation between body type, race, and ethnicity.

On a broader spectrum, this thesis represents the importance of celebrity-endorsed advertisements in cosmetic branding. According to Kamins (1990), consumers consider 
"what is beautiful, is good" and advertisers have chosen attractive celebrities to market their beauty products, as they know consumers will have a higher degree of believability and desire to look like the celebrity. Advertisers gain the ability to recognize what celebrities should be used for a specific type of cosmetic product has given the cosmetic company the ability to market their product more effectively as consumers want to achieve the same look as the celebrity. Social sciences and marketing research show that an attractive face that advertises a product "facilitates attitude change towards issues, products, and ad-based evaluations" (Kamins, 1990, p. 4). Understanding the importance in the relationship between celebrity and advertisement is a significant marketing strategy. According to McCracken (1989), "meanings pass from celebrity to product and from product to consumer" (p. 310). By using a celebrity to market a cosmetic product, companies are gaining a stronger consumer relationship.

The results of this study also suggest that cosmetic companies advertising their products during the years of 2008-2013 have for the majority remained using nonminority celebrities. According to the most recent U.S. Census, which was conducted in 2010, there was a total of $308,745,538$ Americans in the United States. Of those Americans, $72.4 \%$ were Caucasian, $12.6 \%$ of them were African American, and $16.3 \%$ of them Hispanic. All three races increased their population by state from the last census done in 2000: Caucasian 5.7\%, African American 12.3\%, and Hispanic 43.0\% (2010 Census Data). This study shows that there has been a minimal increase of race and ethnicity over the past five years which suggests that advertisers may not be as concerned with reaching out to other minority groups. However, the study shows that in 2010 there was a significant increase in non-minority celebrities used in cosmetic advertisements 
compared to the other years. In 2009 , there was $67.6 \%$ non-minority celebrities used in celebrity-endorsed cosmetic advertisements and 32.4\% minorities. Furthermore, in 2010, only $58.6 \%$ non-minority celebrities were used to endorse cosmetic products, meanwhile $41.4 \%$ of minority celebrities was a close second.

Another objective of this study was to discover why there was change in 2010 in the increase of minority celebrity-endorsed advertisements. A possible reason as to why there was an increase in 2010 in minority celebrity advertising could be due to the rise in percentage of minorities in the U.S. population. According to AdWeek's (2012) article, "The Start of Majority-Minority" states that the "... U.S. is becoming a "majorityminority'-where minority groups account for more than half of the population" (para. 1). In the 2010 U.S. census, for the first time in history, minority births out numbered non-minority births. According to the same poll presented by the Census Bureau: 50.4 percent of the country's population younger than 1 were minorities as of July 1, 2011. This is up from 49.5 percent from the 2010 Census taken April 1, 2010. The population younger than age 5 was 49.7 percent minority in 2011 , up from 49.0 percent in 2010. There were 114 million minorities in 2011, or 36.6 percent of the U.S. population. In 2010, it stood at 36.1 percent (AdWeek, 2012, para. 2-3).

This study reveals that from the sample of 238 celebrity-endorsed advertisements collected from both ELLE and Cosmopolitan magazine, only two race/ethnicities aside from Caucasian celebrities were used: African American and Hispanics. Furthermore, AdWeek (2012) claims that Hispanics are the largest minority group in the U.S. while African-Americans were the second largest minority group in the U.S.:

Nationally, the most populous minority group remains Hispanics, who numbered 
52 million in 2011; they also were the fastest growing, with their population increasing by 3.1 percent since 2010 ... African-Americans were the second largest minority group in the United States, at 43.9 million in 2011 [up 1.6 percent from 2010]. New York had the largest African-American population [3.7 million] (para. 5-7).

According to Carmichael and Francese (2011), "The 2010 census is being released in a very different world than its predecessors. The amount of real-time data on populations and demographics is exploding" (para. 1). With such an increase in minorities during the year of 2010, the study still shows that during the years of 2011, 2012, and 2013 there was another decrease in minority celebrities endorsing cosmetic products. According to The Economist (2011), "Only 7\% of marketing dollars are spent on targeted ethnic campaigns, although nearly half of Americans belong to ethnic minorities ... ad-agency staff need to be more diverse" (para. 8). Overall, this study shows that although the year 2010 had more of an increase in minority celebrity-endorsed advertisements; it has not increased overall within the years of the study (2008-2013). There was a small increase in 2010; however, celebrity-endorsed cosmetic advertisements have remained using Caucasian (non-minority) celebrities for the majority of their advertisements.

However, the rise in percentage of minorities in the U.S. in 2010 and the quick decline in 2011-2013 may not be associated with the overall increase of minorities in the U.S. population in 2010. Establishing the cause of the increase and subsequent decline is speculative and beyond the scope of this quantitative study because the study did not asses this cause and effect. 
Another component of celebrity-endorsed advertisements that was assessed during the study was the relationship between body type and race/ethnicity. Originally the study expected to show that there is a correlation between race/ethnicity and body type. For example, Guzman and Valdivia (2004) identified Latina actress, Selma Hayek as, "petite yet hyper-curvaceous frame [that] embodies the romanticized stereotypical Latina hourglass shape" (p. 212).

Along with Guzman and Valdivia's research, this study can also reveal whether there is a pattern connecting a celebrity's body type with their race and ethnicity. However, the results from this study prove to show that 68 out of the $80(85 \%)$ advertisements dedicated to full body celebrity endorsed cosmetic advertisements were celebrities with bodies that demonstrate an ectomorph shape. According to Tiggemann and Mcgill (2004), magazines are very powerful distributors of models or celebrities who portray an idealistic body image: "Certainly formal content analyses of the visual media (fashion magazines, television advertising, and programming) document a preponderance of young, tall, and extremely thin women who epitomize the current beauty ideal" (p. 24). Although there was an expectation that Caucasian women would embody an ectomorph body style, the thesis shows that the majority of African Americans and Hispanics demonstrate an ectomorph body as well. According to the study, nine out of 14 African American (64.3\%) celebrities and six out six (100\%) Hispanic celebrities portrayed an ectomorph body type.

It is important to note that even though the sample constructed for this study is too small for statistical significance in regards to body type, African Americans show the largest percentage of celebrities that do not depict an ectomorph body type. According to 
the study, out of 60 Caucasian celebrities, $53(88.3 \%)$ of them portrayed an ectomorph body type and $0.12 \%$ of them did not. Out of 14 African American celebrities found, 9 $(64.3 \%)$ of them portrayed an ectomorph body type and $0.36 \%$ did not. Out of 6 Hispanic celebrities found, $100 \%$ of them portrayed and ectomorph body type. Overall, although an ectomorph body type was the most dominant body type found within all races and ethnicities, African Americans showed the most variation within their bodies and figures.

This current study provides empirical information to future researchers who plan to look at the same trends. It was interesting to see how minorities are beginning to become the majority of the population in 2010 and made an impact in celebrity-endorsed advertisements during that year but failed to do so in more recent years. Also, it was interesting to see how ectomorph body types are still being portrayed (regardless of race or ethnicity) when society has been recently stressing the importance of being healthy.

\section{CONTRIBUTIONS AND IMPLICATIONS}

The purpose of this thesis was to determine whether print cosmetic advertisements have increased their use of minority celebrities between the years of 2008-2013. Furthermore, the research attempted to discover if there was a relationship between race/ethnicity and body types found within the celebrity-endorsed advertisements collected. Theoretically, the results found from this thesis contribute to the world of advertising as many of the results can be used for future studies concerning the increase and decrease of minority celebrities used and the consistency in body types seen in print advertising. Understanding the importance of advertising and the impact it has on our society today, this thesis can be used as a stepping stone for other research that would analyze the same variables, especially over a longer period of time. 
This thesis provides particular attention to celebrities as they provide more effectiveness when endorsing products. Consumers are more likely to pay attention to advertisements that portray a celebrity. Also, looking at two top fashion magazines was important in this study as they provided a substantial amount of cosmetic celebrityendorsed advertisements.

According to the Association of Magazine Media:

The content of the average consumer magazine is $47 \%$ advertising and $53 \%$ editorial. Many magazines, such as fashion and lifestyle publications, can have up to $70 \%$ of their pages devoted to advertising, which makes the clutter problem particularly acute. Thus, the use of popular celebrities can be a way for an ad to stand out in a cluttered media environment and attract the attention of viewers or readers (Belch \& Belch, 2013, p. 370).

In addition, body image is a constant topic of discussion in society. This thesis supports that the majority of celebrities used in the sample of advertisements portrayed an ectomorph body type. This reiterates the notion that society is still insistent on a "thin" ideal and that what is "thin" is "beautiful." There are many minority celebrities who represent different body types however; the study proved that advertisements are still looking to use thinner models to endorse cosmetic products.

\section{LIMITATIONS AND FUTURE STUDY}

Although this thesis provides information on print celebrity-endorsed advertisements, race/ethnicity, and body image there are some limitations that future research would need to consider. One of the limitations that this research presents would be the restriction on the number of years used from both ELLE and Cosmopolitan 
magazine. Since only the past five years were available for both magazines, it was difficult to accurately analyze the change in race/ethnicity as well as body type. This research strived to show that diversity and race in marketing and how it has changed over the years; however, five years may not be enough to show that change.

Another limitation of the research is the timeframe of the advertisements analyzed. If a more in-depth study was performed of all 12 months of the year, there may have been more of a variety in results, allowing more accuracy in the results.

A final limitation of this study would be how individuals interpret and perceive race and ethnicity. Since there is not one consistent definition of what race and ethnicity is, coders interpreting the celebrity-endorsed advertisements may have used subjectivity in analyzing a celebrity's race and ethnicity.

This thesis provides important findings for future researchers who intend on doing similar studies regarding celebrity endorsed advertisements and their correlation with race, ethnicity, and body type. As mentioned, this research shows that in the past five years only two minority backgrounds were identified. There is a lot of room for future studies to look at why this was the case and why minorities are not being considered to advertise cosmetic products when they are becoming a larger population in the U.S. For example, according to Carmichael and Francese (2011):

The Asian population is the fastest-growing racial or ethnic group in the U.S., but it is even more highly concentrated than the Hispanic population. There are now 14.5 million Asians living in the U.S., up 43\% since 2000. One-third of all U.S. Asians live in California and another $10 \%$ live in New York State. The Asian-adult population rose $47 \%$ (para. 17). 
A future researcher may want to look into why celebrity-endorsed advertisements are not using Asian celebrities to market their products when they are the fastest-growing racial and ethnic group in the United States. This study can be used as an exploratory research in the world of celebrity-endorsed advertising in cosmetic products but more closely related to a celebrity's race, ethnicity, and body type. It provides a strong base for what researchers should look for as the study proved that aside from one year (2010) there has not been an increase in minority celebrities used in advertisements as well as a thin body ideal is still being used to market products.

In terms of further exploratory research this thesis can provide a base for a study that suggests other types of research. This thesis allows researchers to do experimental studies and surveys on the variables provided within this study: celebrities, race, ethnicity, and body type. An experimental study would be able to prove "why" many of these results were found when a content analysis was only able to provide a descriptive analysis. 
A CONTENT ANALYSIS OF CELEBRITY ENDORSED COSMETIC PRODUCTS IN

FASHION MAGAZINES

\section{References}

(2006). The Truth About Diversity In Advertising. Black Enterprise, 36(12), 1.

2010 Census Data. (n.d.). Retrieved November 20, 2014, from

http://www.census.gov/2010census/data/

Asean Cosmetic Documents. (n.d.). Association of Southeast Asian Nations.

Retrieved May 10, 2014, from

http://elib.fda.moph.go.th/fulltext2/word/14697/1.pdf

Bandura, A. (2001). Social Cognitive Theory of Mass Communication. Media Psychology, 3(3), 265-299.

Belch, G., \& Belch, M. (2013). A content analysis study of the use of celebrity endorsers in magazine advertising. International Journal of Advertising, 32(3), 369-389.

Bittar, C. (2004). The New Face of Beauty?. Brandweek, 45(3), 24-28.

Boettger, R., \& Palmer, L. (2010). Quantitative Content Analysis: Its Use in TechnicalCommunication. IEEE Transactions on Professional Communication, 53(4), 346-357. 
Bryant, J., \& Zillmann, D. (2008). Chapter 6: Social Cognitive Theory of Mass Communication. Media Effects: Advances in Theory and Research (p. 34). Mahwah, New Jersey: Lawrence Erlbaum Associates.

Burtt, H. (1983). Psychology of Advertising. Oxford, England: Houghton Mifflin.

Carmichael, M., \& Francese, P. (2011, April 4). Census 2010: Five Surprising $\quad$ Facts Marketers Should Know | News - Advertising Age. Advertising Age News RSS. Retrieved October 11, 2014, from http://adage.com/article/news/census-2010surprising-facts-marketers/149692/

Chapman, T. (2011). Women in American Media: A Culture of Misperception. The International Student Journal, 3(7), 21.

Cortini, M., Vicenti, A., \& Zuffo, R. G. (2010). Celebrity Endorsement and Congruence: An Experimental Study. International Journal of Interdisciplinary Social Sciences, 5(8), 325-326.

Cosmopolitan. (n.d.). SPH Magazines. Retrieved February 14, 2014, from http://www.sphmagazines.com.sg/magazines/cosmopolitan

Cosmopolitan Media Kit. (2013). Cosmopolitan Media Kit. Retrieved May 5, 2014, from http://www.cosmomediakit.com/r5/showkiosk.asp?listing_id=4785073\&category code $=$ miss\&c 
Costanzo, P., \& Goodnight, J. (2005). Celebrity Endorsements: Matching Celebrity and Endorsed Brand in Magazine Advertisements. Journal of Promotion Management, 11(4), 49-62.

ELLE Media Kit. (2013). ELLE. Retrieved February 14, 2014, from http://www.ellemediakit.com/r5/home.asp

Forehand, M., \& Deshpande, R. (2001). What we see makes us who we are: Priming ethnic self-awareness and advertising. Journal of Marketing Research, 38(3), 336348.

Grandpierre, K. (2013, July 2). The Review of Creative Industries and Media. How ELLE magazine conquered the world. Retrieved March 3, 2014, from http://www.inaglobal.fr/en/press/article/how-elle-magazine-conquered-world

Hearst Magazines. (2013). National Magazine Company . Retrieved May 5, 2014, from http://www.hearst.co.uk/magazines/4-Our-Brands.htm

Kamins, M. (1990). An Investigation into the "Match-Up" Hypothesis in Celebrity Advertising: When Beauty May be Only Skin Deep. journal of advertising, 19(1), 4-13. 
Kaur, K., Arumugam, N., \& Yunus, N. M. (2013). Beauty Product Advertisements: A Critical Discourse Analysis. Asian Social Science, 9(3), 61-71.

LaWare, Margaret, and Chrisy Moustatos. "For Skin That's Us, Authentically Us": Celebrity, Empowerment, and the Allure of Antiaging Advertisements." Women's Studies in Communication 36.2 (2013): 189-208. Print.

Marketing with Celebrities . (n.d.). Marketing Schools. Retrieved May 5, 2014, from http://www.marketing-schools.org/consumer-psychology/marketing-withcelebrities.html

Martín-Santana, J. D., \& Beerli-Palacio, A. (2013). Magazine Advertising: Factors Influencing the Effectiveness of Celebrity Advertising. Journal of Promotion Management, 19(2), 139-166.

McCracken, G. (1989). Who Is the Celebrity Endorser? Cultural Foundations of the Endorsement Process.. Journal of Consumer Research, 16(3), 310-321.

Mehrabian, A., \& Blum, J. (1997). Physical appearance, attractiveness, and the mediating role of emotions. Current Psychology, 16(1), 20-23. 
Ogunsiji, S. (2012). The Impact of Celebrity Endorsement on Strategic Brand Management. International Journal of Business and Social Science, 3(Special Issue), 6 .

One message, or many?. (2011, December 31). The Economist. Retrieved October 11, 2014, from http://www.economist.com/node/21542203

Pornpitakpan, C. (2003). The Effect of Celebrity Endorsers' Perceived Credibility on Product Purchase Intention: The Case of Singaporeans. Journal of International consumer Marketing, 16(2), 55-74.

Sebastian, M. (2014, January 22). Fashion Magazines' March Issues: See the Top Five Titles. Advertising Age, 1, 1.

Seitz, V., Razzouk, N., \& Eamsobhan, S. (2007). Celebrity Endorsements in U.S. and Thai Magazines: A Content Analysis Comparative Assessment. Journal of Promotion Management, 13(3/4), 383-398.

Stemler, S. (n.d.). Cohen'S Kappa. SAGE Research Methods. Retrieved October 11, 2014, from http://srmo.sagepub.com/view/encyclopedia-of-measurement-andstatistics/n94.xml

The 3 Somatotypes . (n.d.). Center of Wellness Without Borders. Retrieved May 5, 2014, from http://www.uh.edu/fitness/comm educato 
The Start of Majority-Minority. (2012, May 21). AdWeek. Retrieved October 2014, from http://www.adweek.com/sa-article/start-majority-minority-140665

Tiggemann, M., \& Mcgill, B. (2004). The Role Of Social Comparison In The Effect Of Magazine Advertisements On Women's Mood And Body Dissatisfaction. Journal of Social \& Clinical Psychology, 23(1), 23-44.

Turner, G. (2013). Chapter 1: Understanding Celebrity. Understanding Celebrity (2 ed., pp. 1-30). Los Angeles: Sage.

University of, A. T. (2011, September 21). Analyzing quantitative content analysis data. IAR: Conduct research . Retrieved October 7, 2014, from https://www.utexas.edu/academic/ctl/assessment/iar/research/report/ content-analyze.php

Van der Wald, D. v., Beer, N. d., \& Plessis, N. (2007). Attitudes towards attractive and credible celebrities in advertisements: a survey amongst students. Communicare, 26(1), 44-58.

Weinshenker, N. (2002). ADOLESCENTS AND BODY IMAGE: What's Typical and What's Not. Child Study Center, 6(4), 4. 
Whittler, T., \& Spira, J. S. (2002). Model's Race: A Peripheral Cue in Advertising Messages?. Journal of Consumer Psychology, 12(4), 291-301.

Zeh, R. (2005, November 10). A practical introduction into quantitative Content Analysis. Friedrich-Alexander Universität Erlangen-Nürnberg. Retrieved October 7, 2014, from http://iksz.fsv.cuni.cz/IKSZ-16-version1-CA.pdf 


\section{APPENDIX I. CODING SCHEME}

\section{Celebrity Endorsed Advertisements- Coding Sheet}

Coder:

Date:

\begin{tabular}{lll}
\hline Magazine: & Cosmopolitan & Month: \\
& ELLE & Year:
\end{tabular}

\section{Type of Celebrity:}

Actor/Actress
Artist/ Performer
Athlete
Business Professional
Military

\section{Product Type:}

(Found in Association of Southeast Asian Nations "Definition of Cosmetic Products"

PDF)

Creams, emulsions, lotions, gels and oils for the skin (hands, face, feet, etc.)

Face masks (with the exception of chemical peeling products)

Tinted bases (liquids. pastes, powders)

Make-up powders, after-bath powders, hygienic powders, etc.

Toilet soaps, deodorant soaps, etc.

Perfumes and Cologne

Bath and shower preparations: (salts, foams, oils. gels, etc.).

Depilatories

Deodorants and anti-per spirants

Hair care products

Shaving products (creams, foams, lotions, etc.)

Products for making-up and removing make-up from the face and the eyes

Products intended for application to the lips

Products for care of the teeth and the mouth

Products for nail care and make-up

Products for external intimate hygiene

Sunbathing products

Products for tanning without sun

Skin-whitening products

Anti-wrinkle products

3. The advertisement shows the celebrity's: Face___ Body




\section{The celebrity's body type is a: Ectomorph (are long and lean, with little body fat,} and little muscle. Example: fashion models)

Endomorph (has lots of body fat, lots of muscle, and gain weight easily. They're heavier and rounder individuals. Examples: Football linemen

Mesomorph (are athletic, solid, and strong. They're not overweight and not underweight. Example:

Arnold Schwarzenegger)
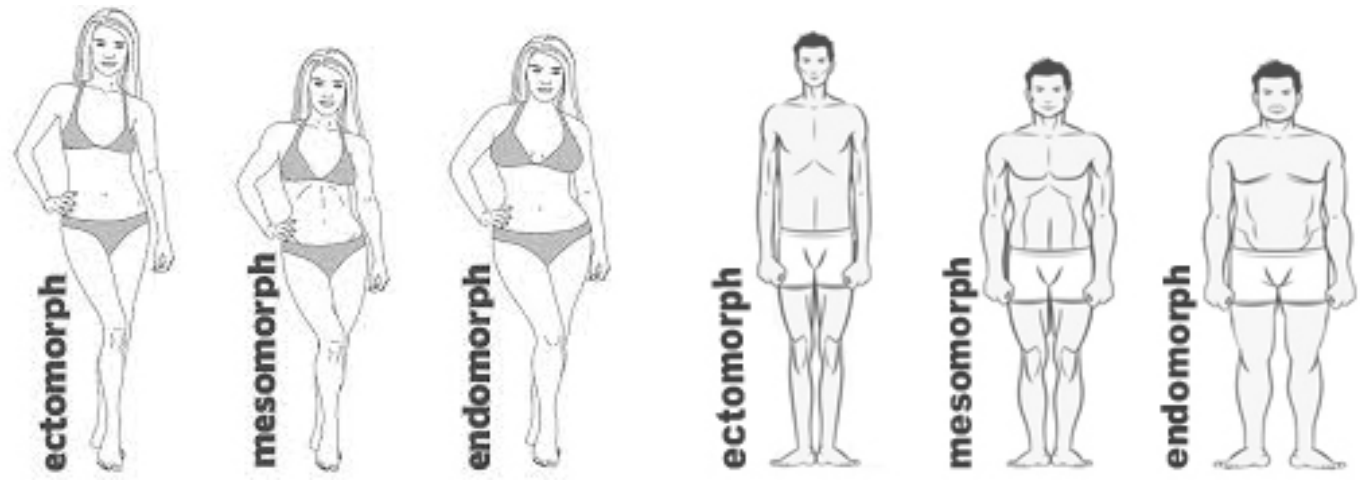

\section{The celebrity's gender is:}

Female

Male

\section{The celebrity's ethnicity is:}

Caucasian (people having origins in any of the original peoples of Europe, the Middle East, or North Africa)

African American (people having origins in any of the Black racial groups of Africa. The Black or African American population includes people who marked their race(s) as "Black, African Am., or Negro" or reported entries such as African American; SubSaharan African (e.g., Kenyan and Nigerian); or Afro-Caribbean such as Haitian and Jamaican)

American Indian (people having origins in any of the original peoples of North and South America [including Central America], and who maintain tribal affiliation or community attachment: Navajo, Blackfeet, Inupiat, Yup'ik, or Central American Indian groups or South American Indian groups) 
Native Hawaiian (people having origins in any of the original peoples of Hawaii, Guam, Samoa, or other Pacific Islands)

Asian (peoples of the Far East, Southeast Asia, Cambodia, China, India, Japan, Korea, Malaysia, Pakistan, the Philippine Islands, Thailand, and Vietnam)

Hispanic/ Latino (person of Cuban, Mexican, Puerto Rican, South or Central American, or other Spanish culture or origin, regardless of race)

Other: please specify: 